\title{
Study by FT-IR Technique and Adhesive Properties of Vulcanized EPDM Modified with Plasma
}

\author{
Renata Patrícia dos Santos ${ }^{1,2}$, Mauro Santos de Oliveira Junior ${ }^{1}$, Elizabeth da Costa Mattos ${ }^{3}$, Milton \\ Faria Diniz ${ }^{3}$, Rita de Cássia Lazzarini Dutra ${ }^{1,3}$
}

\begin{abstract}
The surface of vulcanized ethylene propylene diene terpolymers (EPDM) was modified by $\mathrm{Ar}$ and N2, microwave generated plasma in order to improve adhesion properties. Surface modification was characterized by universal attenuated total reflectance Fourier Transform Infrared [UATR/FT-IR], because it presented lower interference of ingredients of EPDM formulation when compared with other techniques used for the attenuated total reflectance (ATR) to different crystals (ATR/KRS-5 and ATR/Ge). Oxygenated groups were introduced on the surface after treatments which were formed when the activated surface was exposed to the plasma gas. In treatments with nitrogen, oxygen groups and probable nitrogen groups were formed on the surface and could be identified by FT-IR. Reduction in the measurement of the contact angle and an increase in the work of adhesion and in the peel strength [EPDM $X$ Polyurethane (PU)] were observed after the treatment resulted in the improvement of the adhesion properties of the modified surface.
\end{abstract}

KEYWORDS: EPDM, Plasma, Surface characterization, UATR/FT-IR.

\section{INTRODUCTION}

In the aerospace industry, EPDM rubber became an interesting alternative as a thermal protection for rocket motors because of its low density, low processing cost and also because it does not produce toxic compounds while burning, showing advantages in relation to nitrile butadiene rubber (NBR), the copolymer, which is normally used for this application (Moraes et al., 2007a). However, the elastomers of the ethylene-propylene are apolar, presenting low adhesion. With the purpose of improving this characteristic, surface treatment is required (Rapra Review Reports, 2002), without modifying the bulk properties of the polymer (Hegemann et al., 2003; Viadaurre et al., 2002). Plasma treatments are alternatives to reach these characteristics, besides being harmless to the environment (Costa et al., 2008). The disadvantage of plasma is that it requires a vacuum system, thus increasing the cost of the treatment (Moraes et al., 2007b).

The consulted literature mentions some studies in which plasma treatments were used in EPDM and the characterization of the effect on the surface of the elastomer, approaching, in some cases, the sensitivity of the techniques used (Moraes et al., 2007a; Grythe and Hansen, 2006; Awaja et al., 2009).

ATR/FT-IR is a technique that has been used to characterize different polymers. An example is the improved adhesion between polyethylene and the acrylic

1.Instituto Tecnológico da Aeronáutica - São José dos Campos/SP - Brazil 2.Indústria Química Una Ltda. - Itaquaquecetuba/SP - Brazil 3.Instituto de Aeronáutica e Espaço - São José dos Campos/SP - Brazil

Author for correspondence: Rita de Cássia Lazzarini Dutra - Avenida Marechal Eduardo Gomes, 50 - Vila das Acácias | CEP $12228-904$ São José dos Campos/SP - Brazil | E-mail: rclzdutra@iae.cta.br

Received: 19/09/12 | Accepted: 16/01/13 
acid monomer with grafting surface, which provided information to detect the formation of oxygen-containing species on the poly(fluoride) after the glow discharge treatment (Basak et al., 2010). The surface modification of the EPDM, treated in $\mathrm{Ar} / \mathrm{O}_{2} \mathrm{RF}$ plasma, was studied by Basak et al. (2010), and the presence of oxygenated groups was identified in the surface by ATR/FT-IR (ZnSe crystal) and XPS (X-Ray Photoelectron Spectroscopy). A long treatment led to the reduction of the adhesion strength; the author reports this behavior with the reduction of surface energy and the antiadherent nature of sulphur blooming.

Grythe and Hansen (2006) studied the effect of Ar, $\mathrm{O}_{2}$ and $\mathrm{N}_{2}$ plasmas on EPDM films (casting) and differences were revealed through atomic force microscopy (AFM), to which film surface presented more roughness when treated with $\mathrm{O}_{2}$, and a smoother surface when treated with $\mathrm{N}_{2}$. The biggest change was the presence of oxygen in hydroxyl, carbonyl and carboxyl groups, observed by XPS.

Aiming at the excellent properties of EPDM in the aerospace field, Moraes et al. (2007a) carried out comparative studies on the adhesive properties of untreated $\mathrm{NBR}$ versus the EPDM treated with $\mathrm{N}_{2} / \mathrm{Ar}$ and $\mathrm{N}_{2} / \mathrm{H}_{2} / \mathrm{Ar} \mathrm{RF}$ plasma. The XPS analysis showed that polar groups containing nitrogen and oxygen were incorporated to the surface after treatment. Adhesion strength to the interface EPDM/polyurethane liner improved after treatment, reaching values of interface $\mathrm{NBR} /$ polyurethane liner, system used nowadays.

Moraes et al. (2007c) also studied the adhesion properties of EPDM treated with $\mathrm{N}_{2} / \mathrm{Ar}$ and $\mathrm{O}_{2} /$ Ar plasma reactive ion etching (RIE) by FT-IR. The functional groups formed on the surface were: $\mathrm{C}-\mathrm{N}, \mathrm{C}=\mathrm{N}$ and $\mathrm{C}=\mathrm{O}$, besides $\mathrm{C}-\mathrm{O}$ functional groups, due to the rubber oxidation in $\mathrm{N}_{2} / \mathrm{Ar}$; C-O, C=O, O-C=O, C-O-O and $\mathrm{CO}_{3}$ were generated in $\mathrm{O}_{2} / \mathrm{Ar}$.

Other cutting edge techniques of FT-IR, such as UATR, have stood out for the analysis of different materials when compared to transmission techniques. Basically, studies show there are not significant differences in the fingerprint region, below $1,500 \mathrm{~cm}^{-1}$ for the spectrum obtained by the method of transmission and by UATR (Waltham, 2005; Abibi and Hequet, 2005). In the nondestructive technique UATR of internal reflection, used to analyze solids, powders, liquids and gels, an
IR beam passes through an ATR element, with high refractive index, consisting of $\mathrm{ZnSe}$-diamond or KRS-5diamond, and reaches the sample surface (Fig. 1a).

Another requirement of UATR is the good contact between the crystal and the sample surface. The analysis of probe strength (Fig. 1b) can be adjusted in order to obtain a more appropriate contact, once different pressure levels directly influence the intensities of the obtained ATR spectrum.

In most of the mentioned studies and reviewed literature, it was observed that the use of FT-IR contributed to the characterization of the chemical species formed as a consequence of the treatment used on the polymeric surface. Spectrum of the EPDM and polyolefin treated in plasma was found with ATR, however, the use of UATR is not emphasized, the new-generation of the FT-IR technique (Moraes, 2007c; Weon and Choi, 2009).
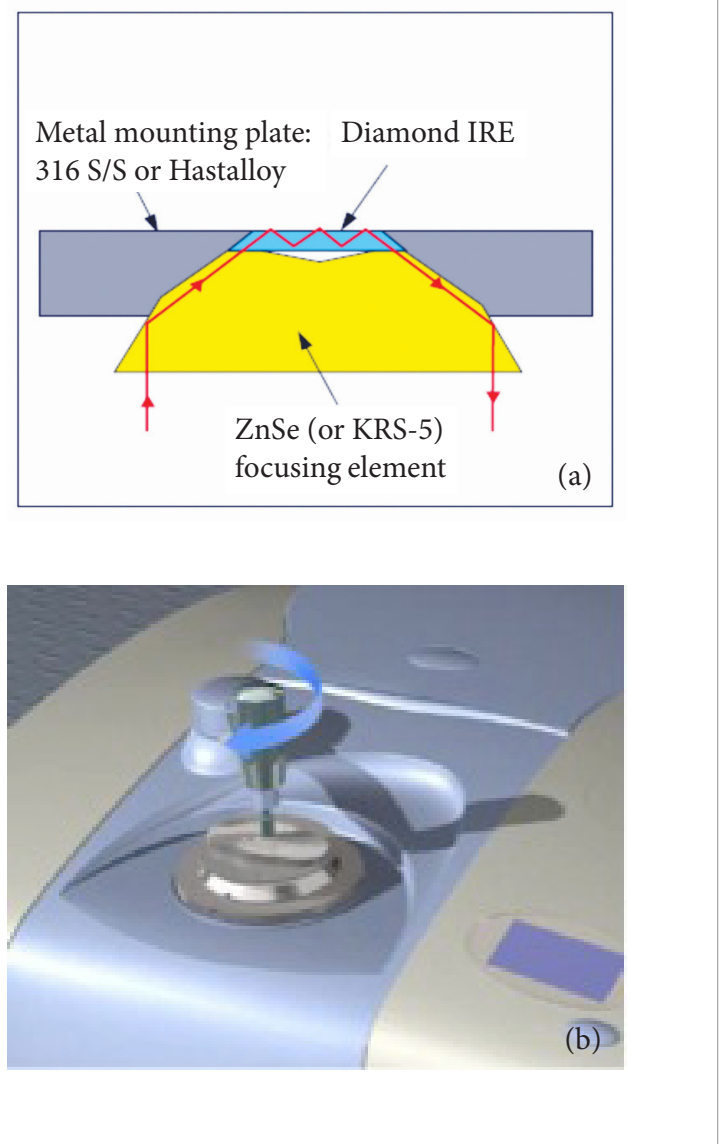

Figure 1. Scheme of UATR (a) probe and (b) top plate (Perkin Elmer). 
Therefore, in this analysis we present the study of surface modification by microwave plasma system, the EPDM rubber with known diene and ethylene content, in which new active groups incorporated on the surface were characterized by UATR, and the evaluation of the adhesion (EPDM versus $\mathrm{PU}$ ) through T-peel strength of the adhesive joint and goniometry.

\section{EXPERIMENT}

\section{Materials}

Samples of EPDM rubber with different diene (ethylidene-norbornene) and ethylene content, one with high diene content (3-6\%) and approximate ethylene content of $50 \%$, Nordel IP 4520 , and the other with low diene content $(<1 \%)$ and approximate ethylene content of $42 \%$, Nordel IP 3430 , were both supplied by the Dow Chemical Company. The EPDM rubbers were prepared by the company Flexlab Consultoria e Treinamento Ltda. And the formulations contained $100 \mathrm{phr}$ (parts per hundred) of rubber, $1 \mathrm{phr}$ of carbon black, $2 \mathrm{phr}$ of paraffinic oil, $1 \mathrm{phr}$ of Tetramethylthiuram Monosulfide (TMTM), $0.5 \mathrm{phr}$ of Mercaptobenzothiazole (MBT), $0.5 \mathrm{phr}$ of stearic acid, $2 \mathrm{phr}$ of $\mathrm{ZnO}$ and $1 \mathrm{phr}$ of sulfur. The rubber was vulcanized at $190^{\circ} \mathrm{C}$ for $12 \mathrm{~min}$.

\section{Soxhlet extraction}

From 1.0 to $1.5 \mathrm{~g}$ of EPDM rubber wrapped in filter paper was used; $100 \mathrm{~mL}$ of acetone was added to a bottom flask. The sample, already wrapped in a filter paper, was placed in the Soxhlet extractor which was connected to the flask. The condenser was connected to the extractor for water circulation to foil the thermostatic bath during the entire extraction process. Extraction was carried out for 8 hours. The excess solvent was transferred to a flask and taken to the oven for 20 to 30 minutes for solvent evaporation, and the residue was analyzed by FT-IR.

\section{Ultrasonic cleaning}

The samples of EPDM rubber were ultrasonically cleaned at a $37 \mathrm{kHz}$ frequency in a stainless-steel tank, under usual cleaning conditions (Peters, 1996). They were immersed in Unalimp WB 2151 solution (detergent) supplied by the chemical industry Una Ltda. It was diluted (4:21) and taken to the ultrasonic tanks for 300 seconds at $60^{\circ} \mathrm{C}$. After the cleaning, they were rinsed in water also at $60^{\circ} \mathrm{C}$ for 3 minutes. Samples were then taken to the oven at $64^{\circ} \mathrm{C}$ (Tecnal, model TE-394/2) for 20 minutes; then, they were treated in plasma, after approximately 18 hours of cleaning.

\section{Contact angle measurement}

Contact angle measurements were performed using a Standard Automated Digital Goniometer model 500-00 of Ramé-Hart Inc., with the software DROPimage Advanced for calculation. Obtained contact angle was 4 to 7 , in different points, by dropping deionized water.

\section{Plasma treatment}

The plasma for this study was generated in a microwave-excited plasma reactor that consists of a rectangular section chamber $230 \mathrm{~mm}$ wide, $80 \mathrm{~mm}$ high and $500 \mathrm{~mm}$ deep with a door for observation and for insertion and withdrawal of samples. There is a mechanical vacuum pump for reduction of the internal pressure of the chamber (Edwards model E2M18). The electric discharge was obtained by magnetron $(2.45 \mathrm{GHz})$. Experiments were performed using Ar and $\mathrm{N}_{2}$ gas flow rate of $20 \mathrm{sccm}$ (standard cubic centimeters per min). The times ranged from 10 to 300 seconds.

\section{T-peel strength measurements (EPDM $x$ PU)}

For the evaluation of EPDM adhesion (after treatment) versus $\mathrm{PU}$ adhesive versus plasticized polyvinyl chloride (PVC), strips were used to prepare the joints. PVC was chosen because its interface with PU is already known. To prepare the PVC, its surface was cleaned with a paper tissue impregnated with acetone; after the solvent evaporated, polyurethane adhesive was applied. The same polyurethane adhesive was applied on the EPDM surface after the plasma treatment. After water evaporated, since the adhesive is an aqueous dispersion, thin solid adhesive film was formed and heated in hot air, at $64^{\circ} \mathrm{C}$, and immediately placed in contact, EPDM x PU adhesive $x$ PVC, both with adhesive and a pressure of $5 \mathrm{~kg} / \mathrm{cm}^{2}$ was applied for 30 seconds, forming an adhesive joint. Values of the T-peel strength EPDM/PU adhesive/ PVC system were obtained in Emic E 500; a peel rate of $100 \mathrm{~mm} / \mathrm{min}$ was used. 


\section{Analysis by FT-IR spectroscopy}

The analysis was conducted in the IAE/AQI by using the FT-IR Spectrum One PerkinElmer spectrometer (resolution $4 \mathrm{~cm}^{-1}$, gain 1,20 scans), by the ATR technique, with KRS-5 (spectral range of 4,000-400 $\mathrm{cm}^{-1}$ ) and $\mathrm{Ge}$ (spectral range of $4,000-700 \mathrm{~cm}^{-1}$ ) crystals, both at $45^{\circ}$, and using the universal accessory UATR (spectral range of 4,000-550 $\mathrm{cm}^{-1}$ ), containing ZnSe and diamond, $100 \mathrm{~N}$ pressure. The transmission FT-IR technique was used to analyze the extracted residue from the rubber (resolution of $4 \mathrm{~cm}^{-1}$, gain 1, spectral range $4,000-400 \mathrm{~cm}^{-1}, 20$ scans) as liquid film.

\section{RESULTS AND DISCUSSION}

\section{Choice of the FT-IR technique:}

Different FT-IR reflection techniques, ATR (KRS-5 and $\mathrm{Ge}$, with spectral range of $4,000-400 \mathrm{~cm}^{-1}$ and spectral range of 4,000-700 $\mathrm{cm}^{-1}$, respectively) and UATR (spectral range of 4,000-550 $\mathrm{cm}^{-1}$ ), under specific conditions were used to analyze the EPDM surface after plasma treatment. This study aims to select the most appropriate accessory to characterize the modified surface. Among these techniques, according to Fig. 2 and 3, the UATR showed lower interference of the bands in the other ingredients of the formulation, regardless of the rubber grade (Nordel IP 3430 or 4520), showing only the rubber bands. Therefore, this technique was chosen to characterize the treated rubbers.

Bands that characterize the EPDM rubbers are found in their wavenumbers, attributed to their vibrational modes: asymmetrical stretching (va) of the $\mathrm{CH}_{2}$ group at $2,920 \mathrm{~cm}^{-1}$, symmetrical stretching (Vs) at $2,850 \mathrm{~cm}^{-1}$, asymmetrical $(\delta \mathrm{a})$ and symmetrical bending $(\delta \mathrm{s})$ of $\mathrm{CH}_{3}$ at $1,460 \mathrm{~cm}^{-1}$ and $1,377 \mathrm{~cm}^{-1}$, respectively, and in plain bending or rocking $(\rho)$ of $\mathrm{CH}_{2}$ at $721 \mathrm{~cm}^{-1}$ (Awaja et al., 2009; Babbit, 1978; Basak et al., 2010).

Figure 4 shows the transmission FT-IR spectrum of the residues extracted from the rubbers (Nordel IP 3430 and 4520). The extracts were obtained by Soxhlet, in acetone and heated up (Smith, 1979). The attributions of the bands were possible because the composition of the rubbers is known, thus enabling to

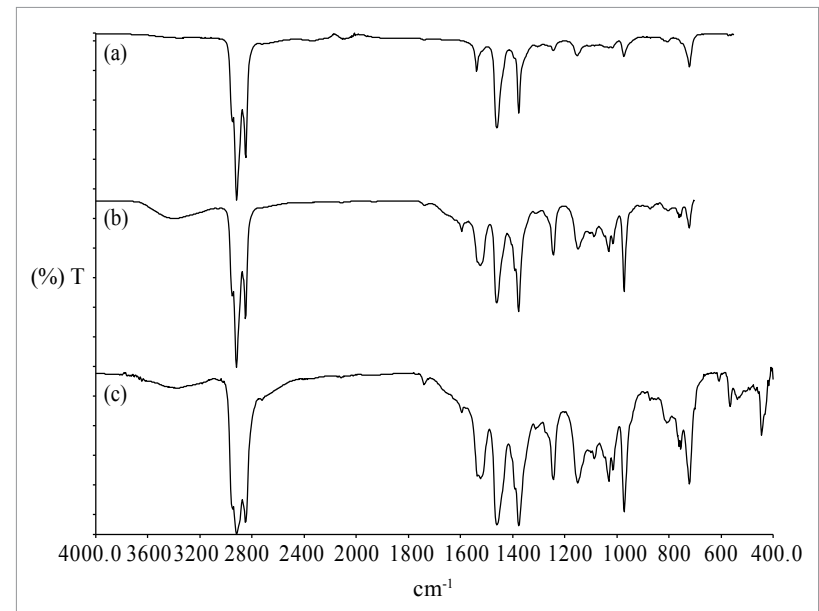

Figure 2. FT-IR spectrum of the surface of EPDM Nordel IP 3430, after being ultrasonically cleaned (a) UATR, (b) ATR/Ge and (c) ATR/KRS-5.

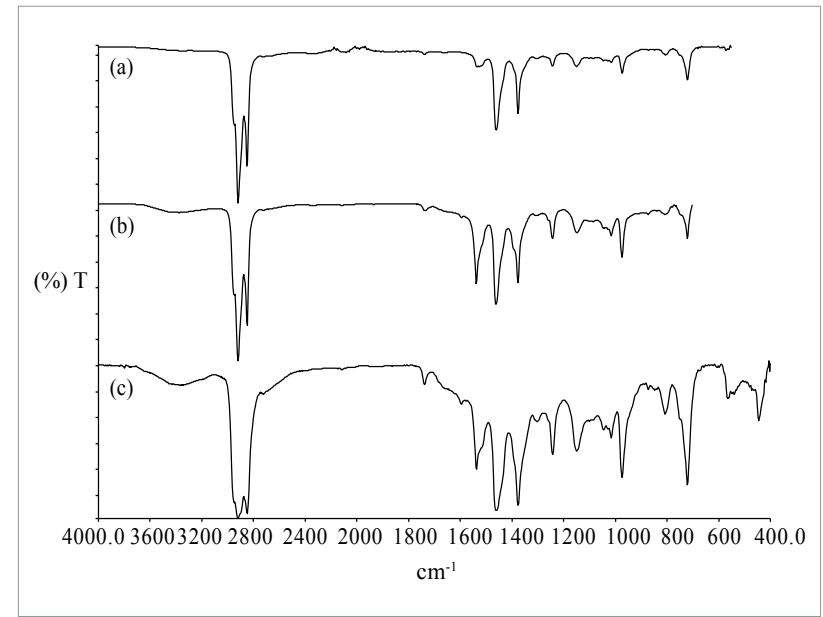

Figure 3. FT-IR spectrum of EPDM surface Nordel IP 4520, after being ultrasonically cleaned (a) UATR, (b) ATR/Ge and (c) ATR/KRS-5.

find in the spectrum IR of the soluble ingredients in the used solvent (Dutra et al., 1995).

Bands of the $\mathrm{CH}_{2}$ group in Fig. 4 (a) and (b) are attributed to the presence of paraffinic oil at 2,922 and $2,853 \mathrm{~cm}^{-1}$ and $\mathrm{CH}_{3}$ at 1,463 and $1,380 \mathrm{~cm}^{-1}$. The $\mathrm{C}=\mathrm{O}$ groups were observed in 1,739 , and $\mathrm{C}-\mathrm{O}$ in $1,243 \mathrm{~cm}^{-1}$ (Smith, 1979). These oxygenated groups indicate the possible presence of the ester group of zinc stearate formed during vulcanization, after the reaction of stearic acid with $\mathrm{ZnO}$ was added to the formulation (Awaja et al., 2009). 


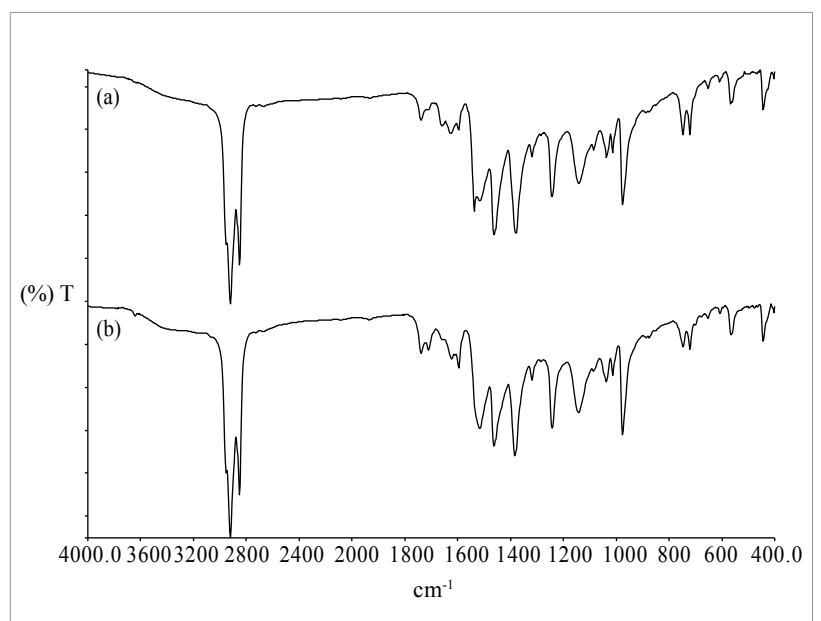

Figure 4. Transmission FT-IR spectrum, obtained of residue of rubbers obtained after extraction in acetone - (a) Residue extracted of Nordel IP 3430 and (b) Residue extracted of Nordel IP4520.

$\mathrm{CH}$ absorption of aromatics was observed by the presence of $\mathrm{MBT}\left(1,597 \mathrm{~cm}^{-1}\right)$, Ring- $\mathrm{CH} 1$ and 2 was disubstituted (ortho) in $748 \mathrm{~cm}^{-1}$. The $\mathrm{RSCH}_{3}$ group was confirmed by the band in $1,319 \mathrm{~cm}^{-1}$. In this case, the presence of thioamides at $1,623 \mathrm{~cm}^{-1}$ could be attributed to the TMTM, besides deformation at $1,142 \mathrm{~cm}^{-1}$ of C-N (Smith, 1979).

\section{FT-IR analysis after ultrasonic cleaning}

The results of the surface analysis by UATR show that the ultrasonic cleaning removed part of the components that bloomed to the surface of the rubber. And it can be confirmed when compared to the spectrum of the rubbers cut in half, in the longitudinal direction, when the internal part was analyzed (Fig. 5).

FT-IR analysis of EPDM surface, after treatment with $\mathrm{Ar}$ and $\mathrm{N}_{2}$ plasma:

Figures 6 and 7 present the FT-IR spectrum of the Nordel IP 3430 and Nordel IP 4520 rubbers, both untreated and treated with $\mathrm{Ar}, \mathrm{N}_{2}$ plasma, respectively. In the treatment with $\operatorname{Ar}$ (10 seconds and 120 seconds) plasma for Nordel IP 3430, Fig. 6 (b), (c) and (d), oxygenated groups were created and were justified by the presence of the bands $\mathrm{OH}$ at $3,500 \mathrm{~cm}^{-1}$ and $-\mathrm{COOH} / \mathrm{C}=\mathrm{C}$ between 1,520 and $1,560 \mathrm{~cm}^{-1}$. Now for the treatment of 300 seconds with $\mathrm{Ar}$, there is was the formation of $\mathrm{C}-\mathrm{O}$ (1,000 to $\left.1,100 \mathrm{~cm}^{-1}\right)$. Also, $\mathrm{OH}\left(650\right.$ to $\left.769 \mathrm{~cm}^{-1}\right)$ (Silverstein and

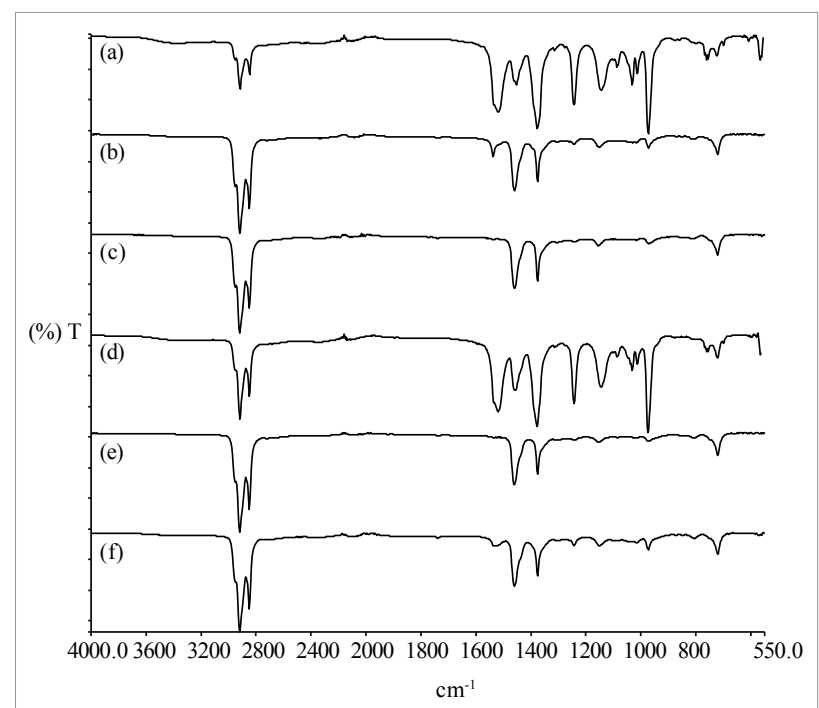

Figure 5. FT-IR spectrum obtained by UATR of rubber Nordel IP 3430 (a) before submitting it to ultrasonic cleaning (b) after cleaning, (c) rubber cut in half. Spectrum of rubber Nordel IP 4520 (d) before submitting it to ultrasonic cleaning (e) after cleaning and ( $f$ ) rubber cut in half.

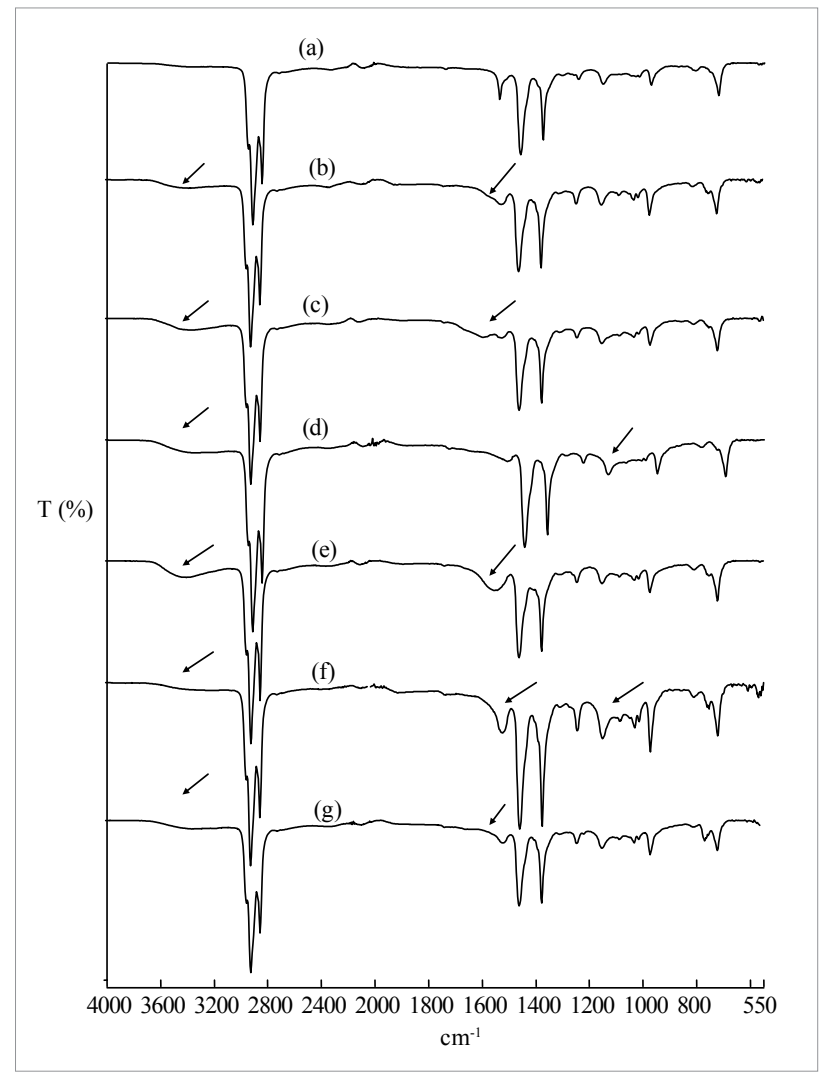

Figure 6. UATR/FT-IR spectrum of Nordel IP 3430: (a) Reference sample, rubber analyzed after ultrasonic cleaning, untreated, (b) rubber treated in Ar plasma, 10 seconds, (c) 120 seconds, (d) 300 seconds; and in $\mathrm{N}_{2}$ plasma for (e) 10 seconds, (f) 120 seconds, and (g) 300 seconds. 
Webster, 2000) to Nordel IP 4520 in Ar plasma (10 seconds and 120 seconds), Fig. 7 (b) and (c), oxygenated groups were also formed and justified by the presence of the bands C-O (1,000 to $\left.1,100 \mathrm{~cm}^{-1}\right)($ Smith, 1979) and OH. Although argon is an inert gas, the incorporation of oxygenated groups is common. During the treatment, free radicals are formed and react with oxygen when in contact with the atmosphere (Viadaurre et al., 2002).

In the treatment with $\mathrm{N}_{2}$ plasma, oxygenated and possible nitrogenated groups were formed. Some nitrogenated groups absorb at wavenumbers as much as oxygenated groups, thus there is possibility of overlapping bands. The presence of bands was observed in the same groups, such as: $\mathrm{OH}$ at $3,500 \mathrm{~cm}^{-1}$ and/or N-H at a range of $3,200-3,500 \mathrm{~cm}^{-1}$ and $-\mathrm{COOH}\left(1,520\right.$ to $1,560 \mathrm{~cm}^{-1}$ ) (Figs. 6

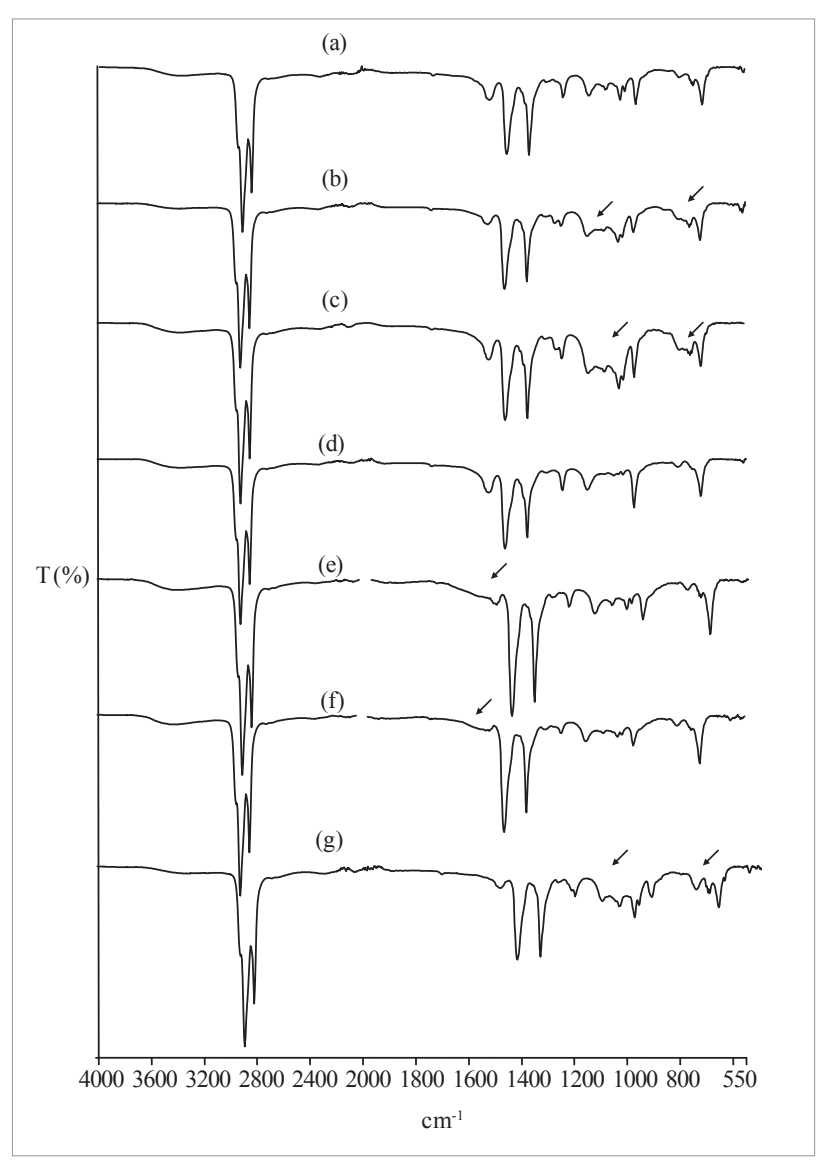

Figure 7. UATR/FT-IR spectrum of Nordel IP 4520 (a) Reference sample, rubber analyzed after ultrasonic cleaning, untreated, (b) rubber treated in Ar plasma, 10 seconds, (c) 120 seconds, (d) 300 seconds; and in N2 plasma for (e) 10 seconds, (f) 120 seconds, and (g) 300 seconds. and 7e, f, g), C-O (1,000 to $\left.1,100 \mathrm{~cm}^{-1}\right)$ and/or C-N(1,0001,200 $\mathrm{cm}^{-1}$ ) (Figs. 6f and 7g) (Peters, 1996; Babbit, 1978; Basak et al., 2010), OH (650 to $769 \mathrm{~cm}^{-1}$ ) (Silverstein and Webster, 2000) (Fig. 7g). The presence of nitrogenated groups must be confirmed by XPS, because there is a band overlap in the FT-IR analysis. In literature, it is possible to find that oxygen has high permeability, and could migrate to the layer below the surface (Viadaurre et al., 2002), possibly being identified by FT-IR, whereas nitrogen is a less permeable gas, modifying the surface in nanometer content, being detected by XPS (Moraes, 2007c).

\section{Contact angle measurement}

The contact angle technique was used to characterize the surface properties of untreated and treated samples of EPDM rubber Nordel IP 3430 and 4520. As soon as the treatments were conducted, by dripping deionized water over the rubber surface and using an appropriate syringe, the contact angles were measured after the treatments.

In this case, water was chosen for the study of the surface, because the adhesive used in the T-peel strength measurements, which will be discussed later on, has a polar characteristic (polyurethane adhesive). However, several pure liquids may be used to estimate the surface free energy of a material by means of various thermodynamic theories (Rapra Review Reports, 2002).

The results (Table 1) show reduced values of contact angle after all the treatments. This reduction indicates change in polarity, greater affinity for water, which consequently leads to the improvement of the adhesive properties of surfaces.

As it is known, the work of adhesion (WA) was calculated with the Young-Dupré equation (Eq. 1), using the surface tension $(\gamma L V)$ and the contact angle of the liquid on the surface (Fleming et al., 2010). Thus, when there is complete wetting, it means the liquid spread completely on the surface, and the work of adhesion reaches its maximum value.

$W_{A}=\gamma^{L V} \cdot[\cos (\theta)+1]$

Samples treated with argon and nitrogen plasma for only 10 seconds showed reduction in contact angle for both Nordel IP $3430\left(54.2^{\circ}\right.$ and $\left.57.7^{\circ}\right)$ and Nordel IP 4520 $\left(52.6^{\circ}\right.$ and $\left.50.8^{\circ}\right)$, respectively. 


\section{T-peel strength measurements}

Figure 8 shows the T-peel strength values of EPDM/Polyurethane adhesive/PVC joints obtained from the EPDM rubbers both untreated and treated with plasma. An improvement was observed after treatments, except for Nordel IP 3430 at Ar/10 s.

With the treatment time of 120 seconds $\left(\mathrm{Ar}\right.$ and $\left.\mathrm{N}_{2}\right)$, the values of T-peel were closer between the two EPDM

Table 1. Contact angle and work of adhesion of untreated and treated Nordel IP 3430 and 4520 by plasma.

\begin{tabular}{|c|c|c|c|c|}
\hline \multirow{2}{*}{$\begin{array}{l}\text { Treatment conditions } \\
\text { [gas/time] }\end{array}$} & \multicolumn{2}{|c|}{ EPDM Rubber - Nordel IP 3430} & \multicolumn{2}{|c|}{ EPDM Rubber - Nordel IP 4520} \\
\hline & Contact angle $\left({ }^{\circ}\right]$ & $\begin{array}{l}\text { Work adhesion } \\
{[\mathrm{mN} / \mathrm{m}]}\end{array}$ & Contact angle $\left({ }^{\circ}\right]$ & $\begin{array}{l}\text { Work adhesion } \\
{[\mathrm{mN} / \mathrm{m}]}\end{array}$ \\
\hline Untreated & $122.4 \pm 0.5$ & $33.8 \pm 0.8$ & $117.9 \pm 0.2$ & $38.7 \pm 0.2$ \\
\hline $\mathrm{Ar} / 10 \mathrm{~s}$ & $68.2 \pm 1.1$ & $99.8 \pm 1.3$ & $65.4 \pm 0.8$ & $103.2 \pm 0.9$ \\
\hline $\mathrm{Ar} / 120 \mathrm{~s}$ & $51.7 \pm 1.6$ & $117.9 \pm 1.6$ & $49.3 \pm 1.7$ & $120.2 \pm 1.7$ \\
\hline $\mathrm{Ar} / 300 \mathrm{~s}$ & $52.2 \pm 0.6$ & $117.4 \pm 0.6$ & $44.5 \pm 1.2$ & $124.7 \pm 1.0$ \\
\hline $\mathrm{N}_{2} / 10 \mathrm{~s}$ & $64.7 \pm 0.1$ & $104.0 \pm 0.2$ & $67.1 \pm 0.6$ & $101.1 \pm 0.7$ \\
\hline $\mathrm{N}_{2} / 120 \mathrm{~s}$ & $60.7 \pm 1.5$ & $108.5 \pm 1.6$ & $51.6 \pm 0.7$ & $118.1 \pm 0.7$ \\
\hline $\mathrm{N}_{2} / 300 \mathrm{~s}$ & $57.1 \pm 0.8$ & $113.5 \pm 1.0$ & $56.2 \pm 0.8$ & $113.5 \pm 1.0$ \\
\hline
\end{tabular}

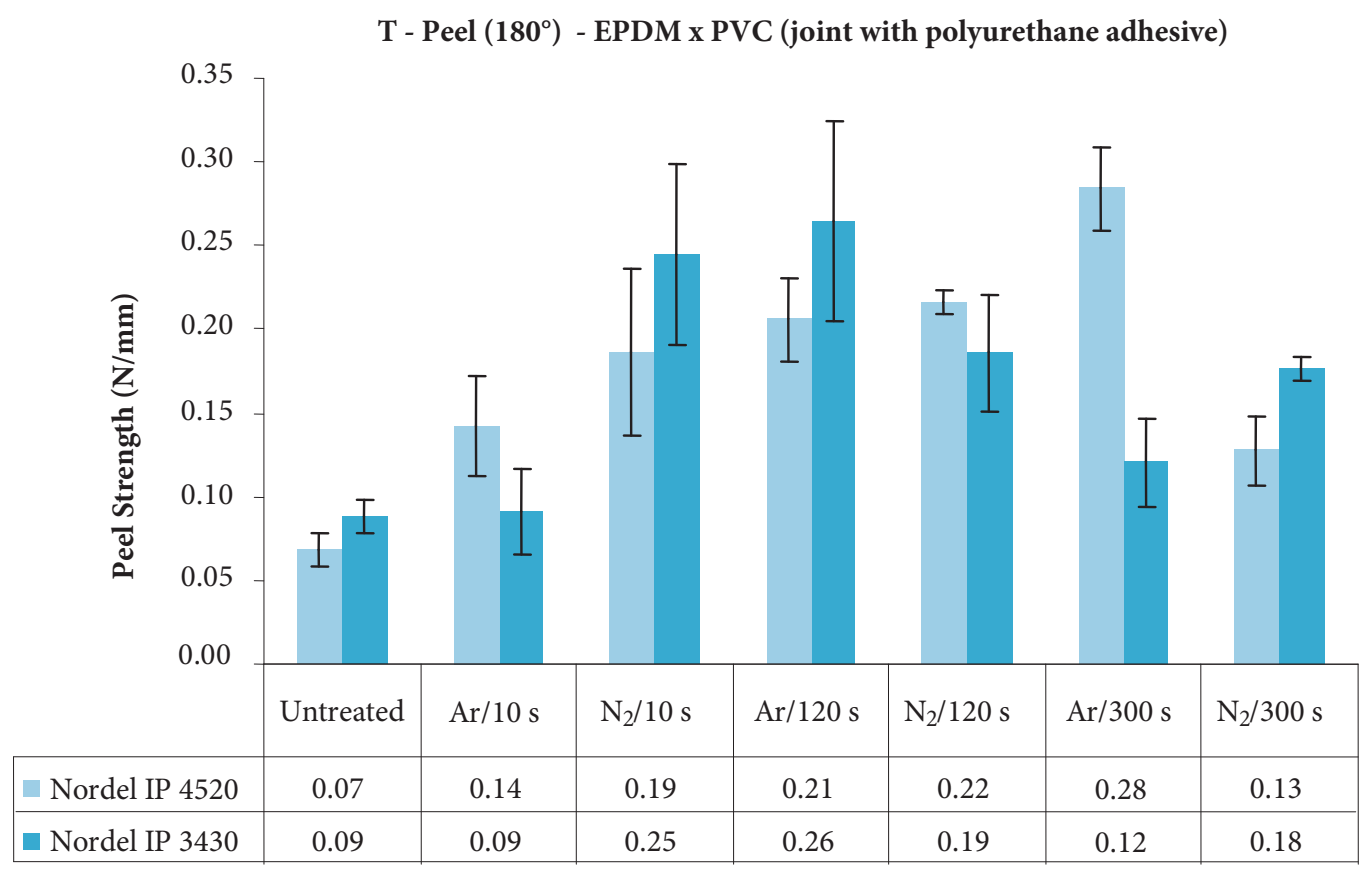

Figure 8. T-peel strength measurements of EPDM/PU adhesive/PVC joints, with Nordel IP 3430 and 4520 , untreated and treated with Ar and N2 (10 seconds, 120 seconds and 300 seconds) plasma. 
grades, whereas with 300 seconds, also with Ar and $\mathrm{N}_{2}$ a larger variation was shown. Plasma processes are highly dependent on the system, the parameters developed for one system usually cannot be adopted for another, and this may explain the different results between the rubbers (Chan and Ko, 1996).

The treatment with $\mathrm{N}_{2} / 10$ seconds shows higher results than that with Ar/10 seconds, probably because $\mathrm{N}_{2}$ is a reactive gas and Ar is an inert gas, and within a shorter time $\mathrm{N}_{2}$ can already activate the surface.

However, long treatment with the same gas that created the functional group on the surface can abstract this formed group or even degrade the surface treated, because of the increased temperature in the ionic atmosphere (Viadaurre et al., 2002).

Before and after the treatment adhesive failure on the EPDM surface (adherent) was observed, this for the EPDM/PU adhesive (Fig. 9). The adhesion strength in the material and intermolecular spacing refer sometimes to the surface energy. This means that cohesion (internal strength of the adhesive itself) was higher than the EPDM/ adhesion (Petrie, 2000). The different values obtained in the T-Peel show a greater or lower affinity with the change in surface.
This observation was possible in this case because the formulation of the polyurethane adhesive has a fluorescent optical brightening agent that allows the visualization of the adhesive film under ultraviolet light (Figs. 9b and c).

Relating the results of contact angle measurements / T-peel strength/FT-IR:

According to Table 1, Nordel IP 4520 presented reduction in contact angle values when treatment time increased from 120 to 300 seconds with Ar plasma. However, the T-Peel strength was increased (Fig. 8), indicating improvement in the adhesives properties, although it was not possible to detect spectrometric changes by IR (Fig. 7d). The same behavior was not observed with Nordel IP 3430, which presented reduction in T-peel, and this can be explained by the difference between the two grades. A possible explanation is that the adhesives properties are not related only to the formation of the functional groups that, in most cases, were detected by FT-IR. They are also related to the alterations in the morphology of the rubber (Sánchez et al., 2001). Basak et al. (2010) related the improvement in adhesion results to the increase of polarity and superficial irregularity
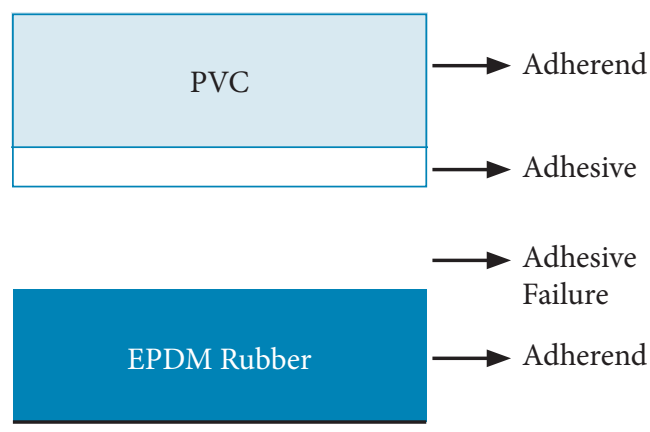

(a)

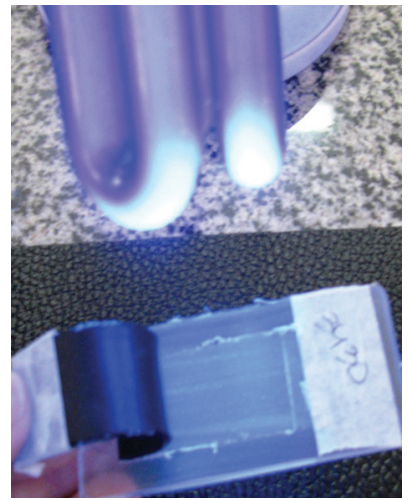

(b)

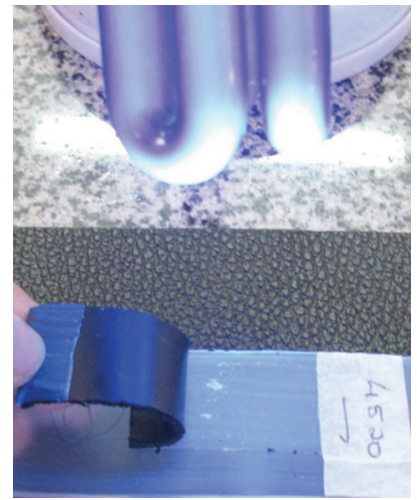

(c)

Figure 9. (a) Scheme of adhesive failure after failures observed after T-Peel test and pictures of the sample: (b) Nordel IP 3430 and (c) Nordel IP 4520. 
which contributes to a good mechanical anchorage of the sample treated in plasma.

So, the best treatment for Nordel IP 4520 was with Ar (300 seconds). Usually, the duration of 120 seconds, as aforementioned, showed similar results for both rubbers.

For the other treatments, in which oxygenated groups and/or possible nitrogenated groups were observed by FT-IR, the improvement in adhesive properties on the EPDM surface can be associated to the increase in surface polarity. Also, the differences between the T-peel strength values are due to the possible differences in the amount of these formed groups and/or change in the morphology surface.

\section{CONCLUSION}

The cleaning of the rubbers' surfaces was necessary to remove the whitish layer formed on them. The evaluation of these surfaces before and after cleaning was possible by means of the FT-IR reflection technique. Among these characterization techniques by reflection of FT-IR, the use of ATR with Ge and KRS-5 crystals showed higher absorption, which is associated to the agents of the formulation ingredients. This led to the choice of the UATR accessory to eliminate the interference of these bands and detect possible alterations of the surface modified in plasma.

The UATR analysis detected oxygenated groups on the surfaces treated with $\mathrm{Ar}$ and $\mathrm{N}_{2}$ plasma. Possible nitrogenated groups were formed in treatments with $\mathrm{N}_{2}$ plasma, however, nitrogenated groups must be confirmed by XPS.

The treatment time of 120 seconds presented a good option for the treatments in $\mathrm{Ar}$ and $\mathrm{N}_{2}$ plasma, because their results were similar with the two different grades of rubber.

\section{REFERENCES}

Abibi, N. and Hequet, E., 2005, "Fourier Transform Infrared Analysis Of Trehalulose And Sticky Cotton Yarn Defects Using ZnSe-Diamond Universal Attenuated Total Reflectance", Text Res J, Vol. 75, No. 9, pp. 645-652.

Awaja, F. et al., 2009, "Adhesion of polymers", Progress in Polymer Science, Vol. 34, pp. 948-968.

Babbit, R.O., 1978, "The Vanderbilt Rubber Handbook”, R.T. Company, Inc. Vanderbilt, Norwalk, 641p.

Basak, G.C. et al., 2012, "Surface modification of argon/oxygen plasma treated vulcanized ethylene propylene diene polymethylene surfaces for improved adhesion with natural rubber", Applied Surface Science, APSUSC-20806, pp. 1-14.

Basak, G.C. et al., 2010, "Characterization of EPDM Vulcanizates Modified with Gamma Irratiation and Trichloroisocyanuric Acid and Their Adhesion Behavior with Natural Rubber", The Journal of Adhesion, Vol. 86, No. 3, pp. 314-315.

Chan, C.M. and Ko, T.M., 1996, "Polymer surface modification by plasmas and photons", Surface Science Reports, Vol. 24, No. 45.

Costa, T.H.F. et al., 2008, "Caracterização de filmes de poliéster modificados por plasma de $\mathrm{O}_{2}$ a baixa pressão", Revista Matéria, Vol. 13, pp. 66.

Dutra, R.C.L. et al., 1995, "Importância da Preparação de Amostras em Espectroscopia no Infravermelho com Transformada de Fourier (FT-IR] na Investigação de Constituintes em Materiais e Compostos", Polímeros, Vol. 5, pp. 41-47.
Fleming, R.R. et al., 2010, "Plasma treatment of polyacrylonitrile/ vinyl acetate films obtained by the extrusion process", Polymer Bulletin, Vol. 66, pp. 282.

Grythe, K.F. and Hansen, F.K., 2006., "Surface Modification of EPDM Rubber by Plasma Treatment”, Langmuir, Vol. 22, pp. 6109-6124.

Hegemann, D. et al., 2003, "Plasma treatment of polymers for surface and adhesion improvement", Nuclear Instruments and Method in Physics Research B. Vol. 208, pp. 281-286.

Moraes, J.H. et al., 2007a, "Surface improvement of EPDM rubber by plasma treatment”, Journal Phys Appl. Phys, Vol. 40, pp. 7747-7748.

Moraes, J.H. et al., 2007b, "Surface modification of EPDM in r. f. plasma: process optimization and surface characterization". Phys Stat Sol (a), Vol. 204, p. 957

Moraes, J.H. et al., 2007c, "Rapid surface modification of EPDM with oxygen and nitrogen plasmas: a comparative study", J Optoelectron Adv M, Vol. 9, pp. 475-477.

PerkinElmer, "ATR accessories - An overview". Technical Note, FT-IR Spectroscopy.

Peters, D., 1996, "Ultrasound in materials chemistry", J. Mater Chem. Vol. 6, No. 10, pp. 1605.

Petrie, E.M., 2000, "Handbook of adhesives and sealants". McGraw-Hill, New York.

Rapra Review Reports, 2002, "Adhesion and bonding to Polyolefins", pp.5. 
Sánchez, M.D.R. et al., 2001, "Surface modifications of a vulcanized rubber using corona discharge and ultraviolet radiation treatments", J Mater Sci, Vol. 36, pp. 5794.

Silverstein, R.M. and Webster, F.X., 2000, "Identificação Espectrométrica de Compostos Orgânicos", 6 ${ }^{\text {th }}$ Ed, LTC - Livros Técnicos e Científicos Editora, Rio de Janeiro, pp. 84.

Smith, A.L., 1979, "Applied Infrared Spectroscopy", John Wiley \& Sons, New York.
Viadaurre, E.F.C. et al., 2002, "Surface Modification of Polymeric Materials by Plasma Treatment", Mater Res, Vol. 5, pp. 37.

Waltham, 2005, "FT-IR Spectroscopy Attenuated Total Reflectance (ATR)", Technical Note. Catalogue PerkinElmer.

Weon, J.I. and Choi, K.Y., 2009, "Surface characterization and Morphology in Ar-Plasma-Treated Polypropylene Blend", Macromol Res, Vol. 17, pp. 891. 